\title{
Azo or Not: Crystallographic Insights into $\beta$-Naphthol Reds
}

\author{
Matthew P. Heaney, ${ }^{a}$ Daniel K. Unruh, ${ }^{b}$ and Tomče Runčevski*,a \\ ${ }^{\text {a }}$ Department of Chemistry, Southern Methodist University, Dallas, TX 75275, United States. \\ ${ }^{b}$ Department of Chemistry and Biochemistry, Texas Tech University, Lubbock, TX 79409, United States.
}

\begin{abstract}
Naphthol reds are a group of widely used pigments with prominent historical, commercial, and cultural significance. In industry, and especially within the art and heritage community, they are known as azo pigments. However, $\beta$-naphthols, very often, are not azo pigments. Due to enol/keto tautomerization of the 1-arylhydrazone-2naphthol skeleton, these pigments oftentimes crystallize as hydrazones (keto). Therefore, proper characterization is necessary for understanding their intrinsic physicochemical properties and chemical reactivity in the solid state, as well as stability and lightfastness. Here, we focused on two representative $\beta$-naphthol reds, pigment red 40 (PR40) and pigment red 4 (PR4). Using single-crystal X-ray diffraction, we provide decisive proof that both of these pigments are keto/hydrazones in the solid state. Therefore, the frequent yet erroneous designation as azo pigments should be avoided. To confirm the bulk structure, we performed powder

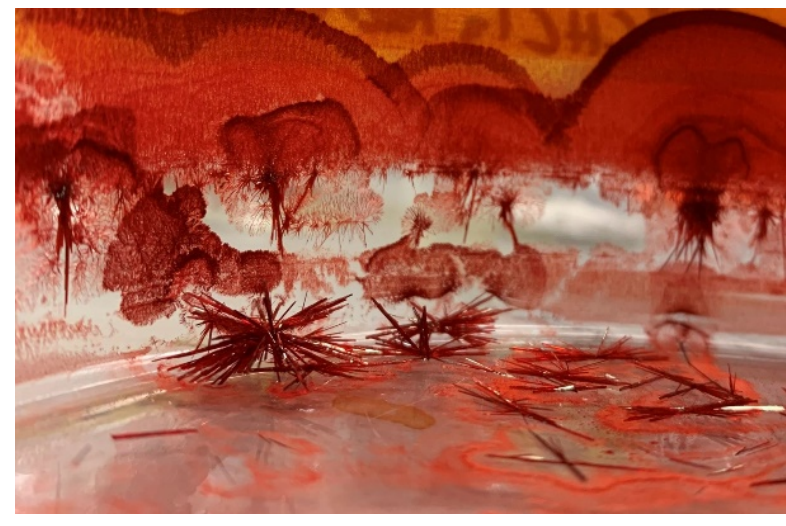
diffraction experiments, followed by Rietveld refinement. We complemented the diffraction experiments with spectroscopic (IR, Raman, UV-vis) and thermal (TGA, DSC) analyses. Furthermore, we studied the lightfastness of both chromophores in solution and solid state. While the solid state pigments were stable over the course of the experiment, UV irradiation of solutions resulted in degradation, which was studied by chromatographic and mass-spec techniques. We hope that this research will bring to light the necessity of proper solid-state characterization of $\beta$-naphthol reds, as well as pigments as a whole.
\end{abstract}

\section{INTRODUCTION}

The color red is deeply ingrained into human culture, society, and history. The earliest instances of color use are with red in the form of red ochre dating back 100,000 years ago. ${ }^{1}$ While prehistoric colorants were mostly inorganic, with time, humans learned to extract and synthesize organic red pigments giving rise to a broad and vibrant spectrum of the color red. ${ }^{2,3}$ In the realm of organic pigments, $\beta$-naphthol reds have been found to play a significant role in historical and cultural works that span centuries and are still relevant in the modern-day., ${ }^{4,5}$ These pigments have been identified in the historic textiles of the indigenous Mapuche civilization. ${ }^{6}$ They have been used to create iconic modern art such as the Rothko murals at Harvard. ${ }^{7,8}$ Today, these pigments are used to print The New York Times, The Sun, Bild, El País, La Repubblica, Le Monde, and other newspapers. ${ }^{9}$ Many $\beta$-naphthol reds have also found their way into our households in cosmetics and everyday objects. ${ }^{10,11}$

$\beta$-Naphthol reds are usually described as azo pigments in industry, and especially within the art and cultural heritage communities. ${ }^{8,12-14}$ This description comes from the use of diazonium salts in coupling reactions with phenols to produce the first "azo" pigments. ${ }^{15}$ However, more often than not, this designation is erroneous. $\beta$-Naphthol reds are based on a 1-arylhydrazone-2-naphthol skeleton (Scheme 1) that can undergo enol/keto tautomerization, providing either azo or hydrazone isomers, or a mixture of both. In solution, this isomerization has been found to give a dynamic equilibrium of both forms with varying ratios. ${ }^{16,17}$ Crystallization is expected to predominantly

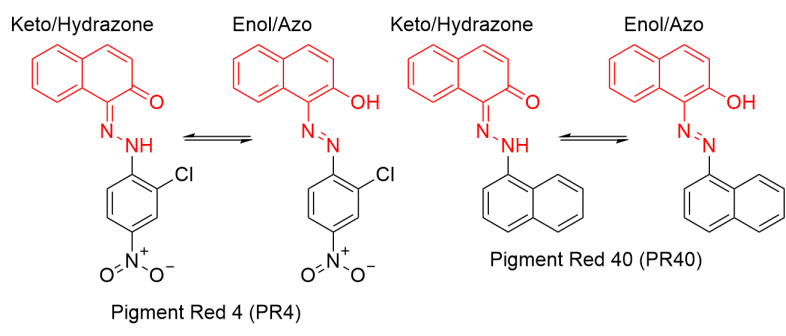

Scheme 1. Schematic representation of the enol/keto (azo/hydrazone) tautomerization of pigment red 4 (PR4) and naphthylamine bordeaux (PR40). The $\beta$-naphthol skeleton is highlighted in red.

stabilize one form, giving either azo or hydrazone solid pigment. The need for proper characterization of the chemical and molecular structure of the solid is far more relevant than mere nomenclature nitpicking: The molecular structure is of fundamental importance for understanding the photophysical properties that give rise to the color (its shade, hue, vibrance, etc.). Furthermore, enol vs. keto tautomers can have radically different decomposition pathways, ${ }^{18,19}$ knowledge of the degradation mechanism is essential for long-term preservation of the pigment, particularly on historic artifacts and iconic art. ${ }^{7,8}$ While spectroscopic analyses can be used to tentatively assign the most stable tautomeric form, more definite information can be 
obtained by single-crystal X-ray diffraction (SC-XRD) with the unambiguous determination of the position of the hydrogen atom. However, growing single crystals of pigments is usually challenged by their low solubility (the underlying difference between dyes and pigments is in their solubility, the former are soluble in the host material, and in various solvents, the latter are not).

In this work, we succeeded in growing high-quality single crystals of two $\beta$-naphthol reds, naphthylamine bordeaux, or pigment red 40 (PR40), and pigment red 4 (PR4), presented in Scheme 1. SC-XRD allowed for definite characterization as keto/hydrazones, proving the enol/azo designation erroneous. The single-crystal crystallographic studies were complemented by a combination of powder X-ray diffraction (PXRD), infrared (IR), Raman, and ultraviolet-visible (UV-vis) spectroscopy, thermogravimetric analyses (TGA), and differential scanning calorimetry (DSC). Furthermore, we report the lightfastness of both chromophores and provide information on some of the major decomposition products, as detected by chromatographic and mass-spec techniques.

\section{EXPERIMENTAL SECTION}

Materials. PR4 and PR40 (diluted with barium sulfate) were purchased by TCI Chemicals and recrystallized before use. Barium sulfate was detected as a second phase in both pigments.

Crystallization of PR4. Pigment red 4 was added to $\mathrm{CHCl}_{3}$ and stirred thoroughly until completely dissolved. The solution was then transferred to a crystallization dish, covered with paper to prevent dust contamination, and then left to evaporate. After 48 hours, all $\mathrm{CHCl}_{3}$ had evaporated, leaving large single crystals (Figure S1 in the SI). The crystals were carefully scraped off the crystallization dish and transferred to a vial.

Crystallization of PR40. Pigment red 40 was added to $\mathrm{Et}_{2} \mathrm{O}$ and stirred thoroughly. Within minutes, the pigment dissolved, and the barium sulfate $\left(\mathrm{BaSO}_{4}\right)$ remained. The solution was then passed through a vacuum filter to separate the undissolved bulk. The filtered solution was added to a crystallization dish, covered with paper to prevent dust contamination, and left to evaporate. After 24 hours, all the $\mathrm{Et}_{2} \mathrm{O}$ had evaporated, and small crystals of PR40 remained (Figure S2 in the SI). These crystals were carefully scraped off the crystallization dish and transferred to a vial.

SC-XRD. Diffraction data for single crystals of PR4 and PR40 were collected on a Rigaku XtaLAB Synergy-i Kappa diffractometer equipped with a PhotonJet-i X-ray source operated at $50 \mathrm{~W}(50 \mathrm{kV}, 1 \mathrm{~mA})$ to generate $\mathrm{Cu} \mathrm{K \alpha}$ radiation $(\lambda=1.54178$ $\AA$ ) and a HyPix-6000HE HPC detector. Crystals were transferred from their vial and placed on a glass slide in polyisobutylene. A Zeiss Stemi 305 microscope was used to identify a suitable specimen for X-ray diffraction from a representative sample of the material. The crystal and a small amount of the oil were collected on a MiTeGen 50 micron MicroLoop and transferred to the instrument where it was placed under a cold nitrogen stream (Oxford 700 series) at 100K. The sample was optically centered with the aid of a video camera to ensure that no translations were observed as the crystal was rotated through all positions. A unit cell collection was then carried out. After it was determined that the unit cell was not present in the CCDC database, CrysAlisPro ${ }^{20}$ was used to calculate a data collection strategy. The crystal was measured for size, morphology, and color. Further data collection information is given in Table 1.
Table 1. Crystal data and structure refinement for PR4 and PR40

\begin{tabular}{|c|c|c|}
\hline $\begin{array}{l}\text { Empirical } \\
\text { mula }\end{array}$ & $-\mathrm{C}_{16} \mathrm{H}_{10} \mathrm{ClN}_{3} \mathrm{O}_{3}$ & $\mathrm{C}_{20} \mathrm{H}_{14} \mathrm{~N}_{2} \mathrm{O}$ \\
\hline Formula weight & 327.72 & 298.33 \\
\hline Temperature/K & $99.9(3)$ & $100.0(2)$ \\
\hline Crystal system & monoclinic & monoclinic \\
\hline Space group & $P 2{ }_{1} / c$ & $P 2_{1} / n$ \\
\hline $\mathrm{a} / \AA ̊$ & $6.94030(10)$ & $10.38690(10)$ \\
\hline $\mathrm{b} / \AA$ & $12.6111(2)$ & $5.81390(10)$ \\
\hline $\mathrm{c} / \AA ̊$ & $15.7945(2)$ & $11.8198(2)$ \\
\hline$\alpha{ }^{\circ}$ & 90 & 90 \\
\hline$\beta /{ }^{\circ}$ & $96.4440(10)$ & $98.1660(10)$ \\
\hline$\gamma /{ }^{\circ}$ & 90 & 90 \\
\hline Volume $/ \AA^{3}$ & $1373.68(3)$ & $706.542(18)$ \\
\hline Z & 4 & 2 \\
\hline$\rho_{\text {calc }} \mathrm{g} / \mathrm{cm}^{3}$ & 1.585 & 1.402 \\
\hline$\mu / \mathrm{mm}^{-1}$ & 2.654 & 0.696 \\
\hline $\mathrm{F}(000)$ & 672.0 & 312.0 \\
\hline Crystal size $/ \mathrm{mm}^{3}$ & $0.172 \times 0.137 \times 0.123$ & $0.135 \times 0.075 \times 0.069$ \\
\hline Radiation & $\mathrm{Cu} \mathrm{K} \alpha(\lambda=1.54184)$ & $\mathrm{Cu} \mathrm{K \alpha}(\lambda=1.54184)$ \\
\hline $\begin{array}{l}2 \Theta \text { range for data } \\
\text { collection } /{ }^{\circ}\end{array}$ & a 8.996 to 155.094 & 10.618 to 154.88 \\
\hline Index ranges & $\begin{array}{l}-8 \leq \mathrm{h} \leq 8,-15 \leq \mathrm{k} \leq 15 \\
-18 \leq 1 \leq 19\end{array}$ & $\begin{array}{l}-12 \leq \mathrm{h} \leq 12,-7 \leq \mathrm{k} \leq \\
6,-14 \leq 1 \leq 14\end{array}$ \\
\hline $\begin{array}{l}\text { Reflections col- } \\
\text { lected }\end{array}$ & -19318 & 12073 \\
\hline $\begin{array}{l}\text { Independent re- } \\
\text { flections }\end{array}$ & $\begin{array}{l}-2867\left[\mathrm{R}_{\text {int }}=0.0406,\right. \\
\left.\mathrm{R}_{\text {sigma }}=0.0230\right]\end{array}$ & $\begin{array}{l}1442\left[\mathrm{R}_{\text {int }}=0.0283,\right. \\
\left.\mathrm{R}_{\text {sigma }}=0.0157\right]\end{array}$ \\
\hline $\begin{array}{l}\text { Data/re- } \\
\text { straints/parame- } \\
\text { ters }\end{array}$ & $2867 / 0 / 208$ & $1442 / 0 / 109$ \\
\hline $\begin{array}{l}\text { Goodness-of-fit } \\
\text { on } \mathrm{F}^{2}\end{array}$ & 1.025 & 1.045 \\
\hline $\begin{array}{l}\text { Final } R \text { indexes } \\
{[I>=2 \sigma(I)]}\end{array}$ & $\begin{array}{l}\mathrm{sR}_{1}=0.0354, \mathrm{wR}_{2}= \\
0.0939\end{array}$ & $\begin{aligned}= & \mathrm{R}_{1}=0.0393, \mathrm{wR}_{2}= \\
& 0.1100\end{aligned}$ \\
\hline $\begin{array}{l}\text { Final } \mathrm{R} \text { indexes } \\
\text { [all data] }\end{array}$ & $\begin{array}{l}\mathrm{s}_{1}=0.0370, \mathrm{wR}_{2}= \\
0.0951\end{array}$ & $\begin{aligned}= & \mathrm{R}_{1}=0.0419, \mathrm{wR}_{2}= \\
& 0.1129\end{aligned}$ \\
\hline $\begin{array}{l}\text { Largest diff. } \\
\text { peak/hole / e } \AA^{-3}\end{array}$ & $0.53 /-0.30$ & $0.19 /-0.20$ \\
\hline
\end{tabular}

Crystal Structure Solution and Refinement. After data collection, the unit cell was re-determined using the full data collection. Intensity data were corrected for Lorentz, polarization, and background effects using CrysAlisPro. ${ }^{20} \mathrm{~A}$ numerical absorption correction was applied based on a Gaussian integration over a multifaceted crystal and followed by a semi-empirical correction for adsorption applied using the program SCALE3 ABSPACK. ${ }^{21}$ The program SHELXT, ${ }^{22}$ was used for the initial structure solution and series of programs was used for the solution and SHELXL ${ }^{23}$ was used for the refinement of the crystal structure. Both of these programs were used within the OLEX2 software. ${ }^{24}$ For PR4, hydrogen atoms bound to carbon and nitrogen atoms were identified in the difference Fourier map and geometrically constrained using the appropriate AFIX commands. For PR40, the site occupancies of atoms O1, H1, and $\mathrm{H} 2$ were constrained to 0.5 due to the non-centrosymmetric 
molecule being centered over an inversion center. Checks for a possible non-centrosymmetric space group did not result in a viable option. Hydrogen atoms bound to carbon and nitrogen atoms were identified in the difference Fourier map and geometrically constrained using the appropriate AFIX commands. PXRD. Diffraction patterns of PR4 and PR40 were collected on a high-resolution laboratory Stoe Stadi-P powder diffractometer, operating in Debye-Scherrer (transmission) geometry. The diffractometer was equipped with a molybdenum X-ray source, and monochromatic Mo-K $\alpha_{1}$ radiation was obtained by a primary Ge(111) monochromator (centered at $0.7093 \AA$ ). Scattered X-ray intensity was simultaneously collected by two highly sensitive, linearly positioned silicon-strip (Mythen Dectris $1 \mathrm{~K}$ ) detectors. Sample preparation involved very gentle grinding of the materials with a mortar and pestle and packing in borosilicate capillaries with a $0.7 \mathrm{~mm}$ diameter. During measurements, the capillary was rotated for improved particle statistics. Diffraction data was collected at room temperature. Diffraction patterns were collected in the $0-75^{\circ} 2 \theta$ range for $24 \mathrm{~h}$. Rietveld Refinements. The crystal structures were refined by the Rietveld method, ${ }^{25}$ using the TOPAS- 6 software. ${ }^{26}$ For the refinement, the crystal structures solved by SC-XRD were used as starting models. Additional crystallographic information and figures of merit are given in Table S1.

IR Spectroscopy. IR spectra were collected with a Fourier transform infrared (FTIR) Thermo Fisher Nicolet iS10 spectrometer. Samples were prepared by grinding $0.01 \mathrm{mmol}$ of pigment with $5.00 \mathrm{mmol}$ of $\mathrm{KBr}$ and then pressed into a pellet.

TGA. Thermogravimetric analyses were carried out using a Netzsch TG 209 F3 Tarsus instrument. Each sample was placed into an alumina crucible and heated from 25 to $600^{\circ} \mathrm{C}$ at a heating rate of $10^{\circ} \mathrm{C} / \mathrm{min}$ under constant nitrogen flow.

DSC. DSC measurements were carried out using a Netzsch DSC 214 instrument. Samples were placed into hermetically sealed aluminum pans. Each sample was heated and cooled at a rate of $5{ }^{\circ} \mathrm{C} / \mathrm{min}$ under constant nitrogen flow in a range from $30{ }^{\circ} \mathrm{C}$ to $240^{\circ} \mathrm{C}$ and $30^{\circ} \mathrm{C}$ to $245^{\circ} \mathrm{C}$ for PR4 and PR40, respectively.
UV-Vis Spectroscopy. UV-Vis spectra were collected with a Shimadzu UV-3600 spectrophotometer using $1 \mathrm{~cm}$ quartz cuvettes and sealed with polytetrafluoroethylene (PTFE) stoppers to prevent evaporation. For reference spectra, PR4 was dissolved in $\mathrm{CHCl}_{3}$, and $\mathrm{PR} 40$ was dissolved in $\mathrm{Et}_{2} \mathrm{O}$ at concentrations of $1.0 \times 10^{-5}$ and $2.0 \times 10^{-5} \mathrm{M}$, respectively.

Photodegradation and Lightfastness Analyses. Photodegradation experiments were carried out using a Newport $300 \mathrm{~W}$ UV-enhanced xenon arc lamp with samples placed approximately $20 \mathrm{~cm}$ away from the light source. A Newport CGA-295 longpass filter was placed between the light source and samples to cut off wavelengths below $295 \mathrm{~nm}$ as a simulation of sunlight, with constant irradiation of $900 \mathrm{~W} / \mathrm{m}^{2}$.

Solutions for liquid-state photodegradation for PR4 and PR40 were made using $\mathrm{CHCl}_{3}$ and $\mathrm{Et}_{2} \mathrm{O}$, respectively, at concentrations of $5.0 \times 10^{-4} \mathrm{M}$. Solutions were contained in $1 \mathrm{~cm}$ quartz cuvettes and sealed with a PTFE stopper to prevent evaporation. Samples of the irradiated solutions were taken every 2 hours for 8 hours for PR40 and every day for 4 days for PR4. Samples were analyzed by GC/MS to evaluate degradation products using an Agilent 6850 Series II GC System and Agilent 5975B VL MSD. In addition, aliquots of samples were taken and diluted to $1.0 \times 10^{-5}$ and $2.0 \times 10^{-5} \mathrm{M}$ for PR4 and PR40, respectively, for UV-Vis measurements.

Solid-state photodegradation plates were prepared by mixing finely powdered pigment with a few drops of mineral oil in a mortar and pestle. The mixture was uniformly spread onto a quartz microscope slide and covered with a second quartz slide. A Raman spectrum was measured using a Horiba Scientific MicroRAM Raman spectrometer with a $785 \mathrm{~nm}$ laser before the plates were placed into the photodegradation apparatus and after 30 hours of irradiation.

\section{RESULTS AND DISCUSSION}

Crystal Structure Description. Single-crystal X-ray analyses allowed for detailed characterization of both pigments. PR4 was found to crystallize in the monoclinic $P 2{ }_{1} / c$ space group, with unit cell dimensions of $a=6.94030(10) \AA, b=12.6111(2) \AA, c$ $=15.7945(2) \AA, \beta=96.4440(10)^{\circ}$, and $V=1373.68(3)$, with
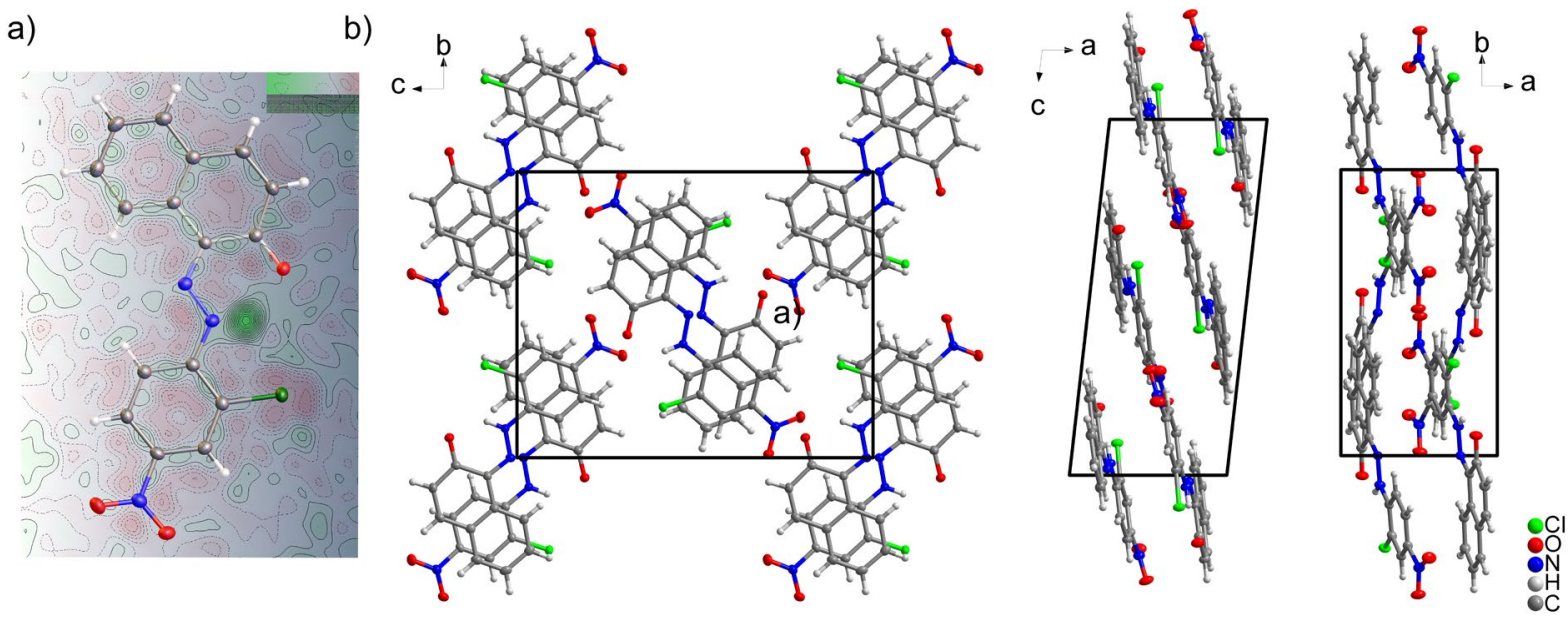

Figure 1. a) Fourier difference map for PR4 showing excess electron density adjacent to the nitrogen atom and absence of excess electron density around the oxygen atom. b) Crystal packing of the structure, viewed along the $a$-, $b$-, and $c$-crystallographic axes. 
a)

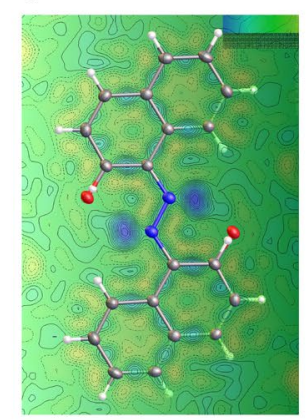

b)

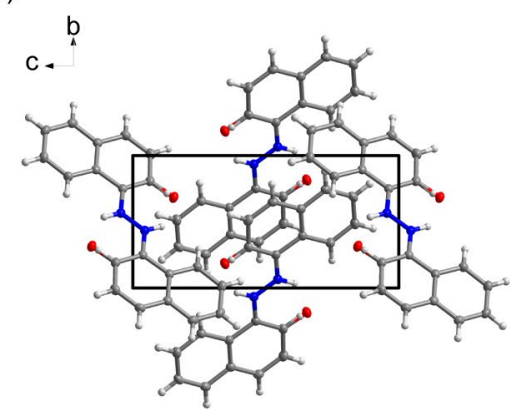

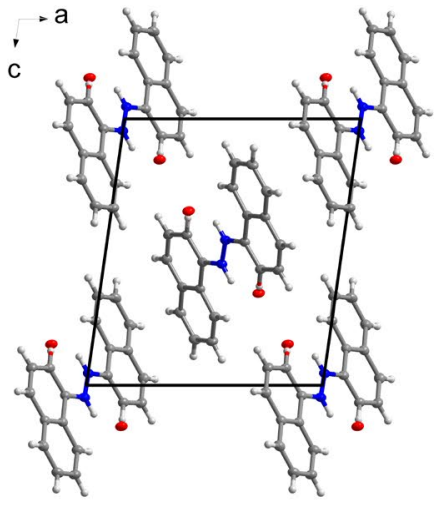

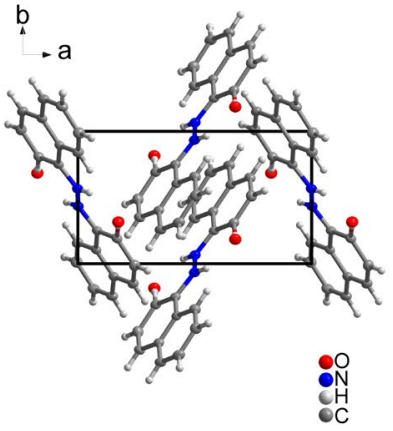

Figure 2. a) Fourier difference map for PR40 showing excess electron density adjacent to the nitrogen atom and absence of excess electron density around the oxygen atom. b) Crystal packing of the structure, viewed along the $a$-, $b$-, and $c$-crystallographic axes. (Note that an inversion symmetry generates a statistically disordered molecule with site occupancies of the keto oxygen and the hydrazone hydrogen atoms being 0.5 ).

one molecule in the asymmetric unit (Figure 1a). Close inspection of the Fourier difference map allowed for the determination of the hydrogen atom as covalently bonded to the nitrogen atom, and forming hydrogen bonding with the oxygen atom of the keto group $(\mathrm{H} \cdots \mathrm{O}$ bond distance of $1.85 \AA$ ). This molecular structure unambiguously confirmed that PR4 crystallizes as the hydrazone and not an azo isomer. The molecular geometry was found to be planar, and the molecular packing can be described as being composed of columns made of head-to-tail stacked molecules (Figure 1b). This crystal packing is guided by $\pi$ stacking of the electron-rich 2-chloro-4-nitrophenol and $\beta$ naphthol molecular fragments.

Similarly, the PR40 pigment was found to crystallize in the monoclinic $P 2{ }_{1} / n$ space group, with unit cell dimensions of $a=$ 10.38690(10) $\AA, b=5.81390(10) \AA, c=11.8198(2) \AA, \beta=$ $98.1660(10)^{\circ}$, and $V=706.542(18)$, with half of the molecule in the asymmetric unit. The inversion symmetry generates a statistically disordered molecule with site occupancies of the keto oxygen and the hydrazone hydrogen atoms set to 0.5 . The molecular structure, as determined by the SC-XRD measurement is presented in Figure 2a. Close inspection of the Fourier difference map allowed for determination of the hydrogen atom as covalently bonded to the nitrogen atom, and forming hydrogen bonding with the oxygen atom of the keto group $(\mathrm{H} \cdots \mathrm{O}$ bond distance of $1.85 \AA$ ). Similar to PR4, PR40 crystallizes as the hydrazone and not the azo isomer. The molecular geometry was found to be planar, building $\pi$ stacked columns (Figure $2 b$ ). Neighboring columns are tilted one relative to another, forming a zig-zag overall molecular packing motif.

Crystallographic Studies of the Bulk. Typically, in the course of SC-XRD analyses, only the high-quality single crystals are selected for data collection (which is colloquially referred to as "crystal picking"). We recognize that there is a possibility for concurrent crystallization of different polymorphs, and potentially different tautomers. To avert this risk of selective crystal picking, we performed PXRD analyses that probes the entire crystalline bulk. Rietveld refinements confirmed that the singlecrystal structures represent the entire sample, and unassigned reflections were not detected (Figure 3).
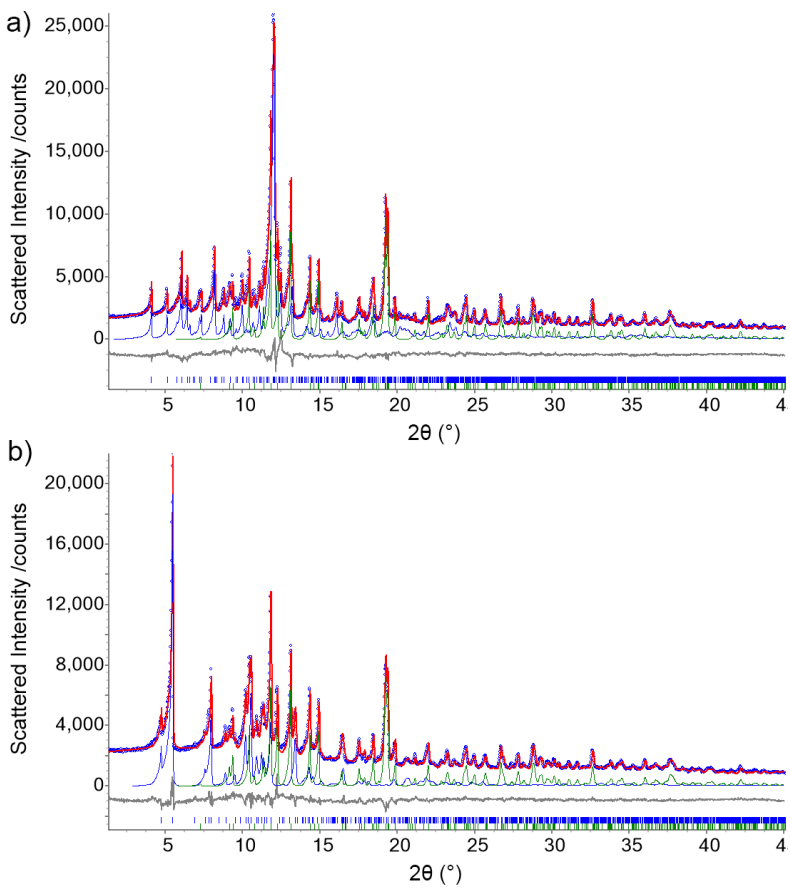

Figure 3. Rietveld refinement plot for a) PR4 and b) PR40. The experimentally collected data (Mo-radiation) is presented as blue dots, the fitted line is presented in red. The simulated pattern or the pigment is given as blue lines, with Bragg reflections as vertical blue bars. Barium sulfate (simulated patterns presented as green lines, Bragg reflections as vertical green bars) was detected with $\sim 11 \mathrm{wt} \%$ for PR 4 and $15 \mathrm{wt} \%$ for PR 40 . 
Vibrational Spectroscopy. Vibrational spectroscopy is a common method used in the identification and characterization of dyes and pigments. ${ }^{27}$ The IR and Raman spectra of PR4 and PR40 are presented in Figure 4. The high-frequency regions of both pigments are characterized by typical aromatic $\mathrm{C}-\mathrm{H}$ stretching vibrations. In the spectrum of PR4, the N-H stretching vibration is observed as a broad band centered around 3400 $\mathrm{cm}^{-1}$, corroborating the hydrazone molecular structure of the pigment. Interestingly, in the IR spectrum of PR40, this band appears to be shifted to $\sim 3750 \mathrm{~cm}^{-1}$. The large shift of the N-H vibrations within both the pigments may be accredited to the presence of para-positioned nitro group on the aryl ring in PR4.
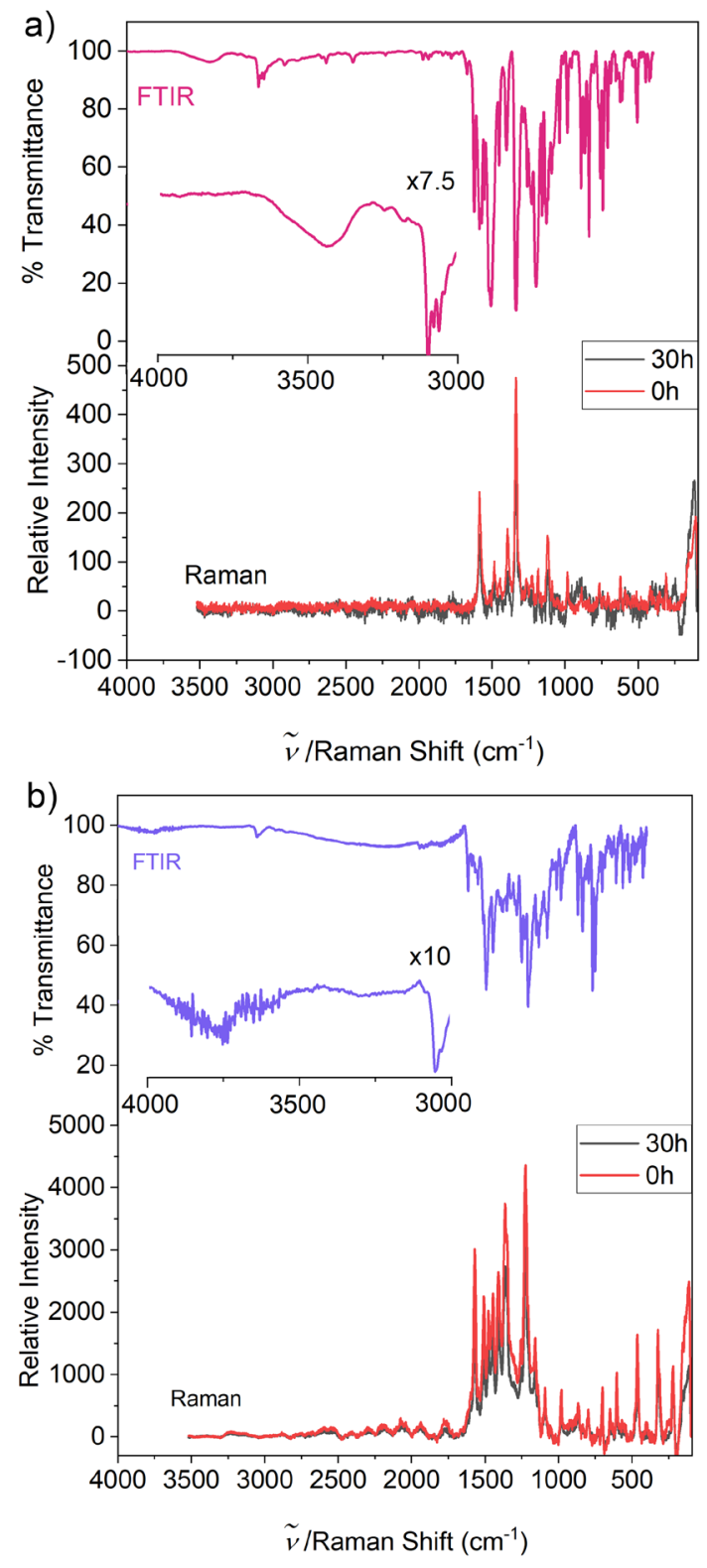

Figure 4. FTIR and Raman spectra (black colored spectra were collected on as-crystalized sample, red colored spectra on a sample irradiated for 30h) for a) PR4 and b) PR40. The insets in the FTIR spectra present magnified high-frequency regions.
The low-frequency region of the IR and Raman spectra is expectedly complicated, with numerous overlapped bands in the fingerprint region. The bands at 1623 and $1616 \mathrm{~cm}^{-1}$ can be tentatively assigned to the keto $\mathrm{C}=\mathrm{O}$ stretching vibrations in PR4 and PR40, respectively. Vibrational spectroscopy may not provide conclusive information about the enol/keto tautomerism of the pigments. However, it still remains an excellent method for chemical identification. Therefore, the fingerprint regions presented in Figure 4 can be used for the characterization of PR4 and PR40 $\beta$-naphthol reds, particularly in art, artifact, and her itage research.

Thermal Stability. PR4 was found to be thermally stable up to temperature of $260^{\circ} \mathrm{C}$, while PR40 was stable up to $250^{\circ} \mathrm{C}$, as shown with the TGA curves presented in Figure 5. Prior thermal decomposition, PR40 undergoes melting at $210{ }^{\circ} \mathrm{C}$ and recrystallizes $195^{\circ} \mathrm{C}$ upon cooling, as shown with the DSC curves. PR4 does not undergo melting before thermal decomposition.

UV-Vis Spectroscopy. Color is the most important physical characteristic of any dye or pigment. Visual representations of the color of the pigments as single-crystals are presented in Figure S1. While the crystals of PR4 did possess a dark red color similar to the commercial reagent, some crystals had a metallic luster, giving them a false green-yellow appearance. Crystals of PR40 had deep red color. The powdered samples of both pigments have deep red color. Figure 6 presents the UV-vis spectra of PR4 and $\mathrm{PR} 40$, recorded in $\mathrm{CHCl}_{3}$ and $\mathrm{Et}_{2} \mathrm{O}$, respectively. PR4 is characterized by broad band centered at $490 \mathrm{~nm}\left(\varepsilon_{\mathrm{abs}}=\right.$ $\left.35300 \mathrm{M}^{-1} \cdot \mathrm{cm}^{-1}\right)$, whereas the adsorption band for PR40 is slightly redshifted to $494\left(\varepsilon_{\mathrm{abs}}=19150 \mathrm{M}^{-1} \cdot \mathrm{cm}^{-1}\right)$.
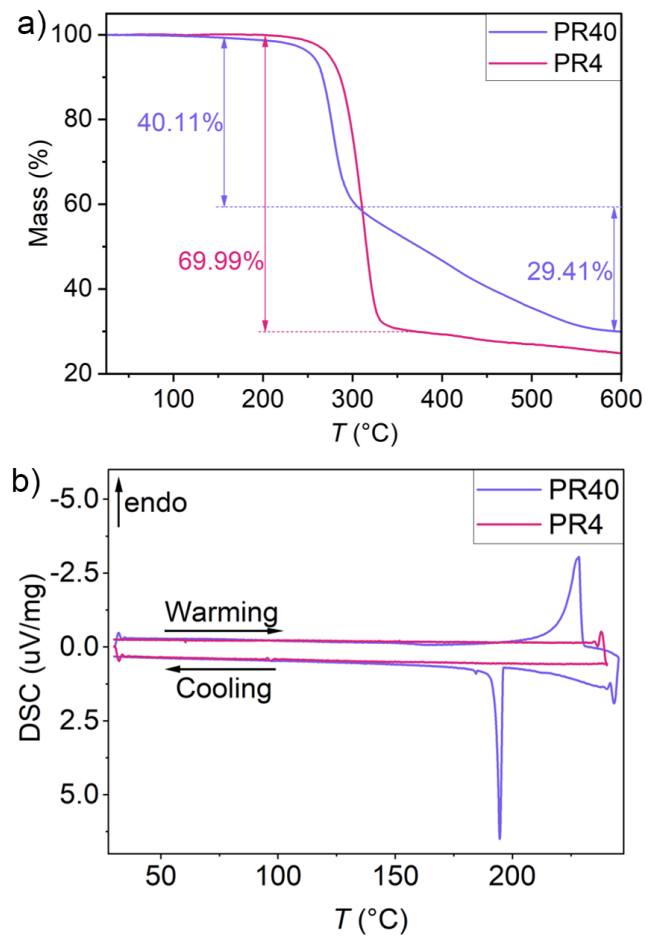

Figure 5. a) TGA and b) DSC curves of PR4 (red) and PR40 (magenta). 

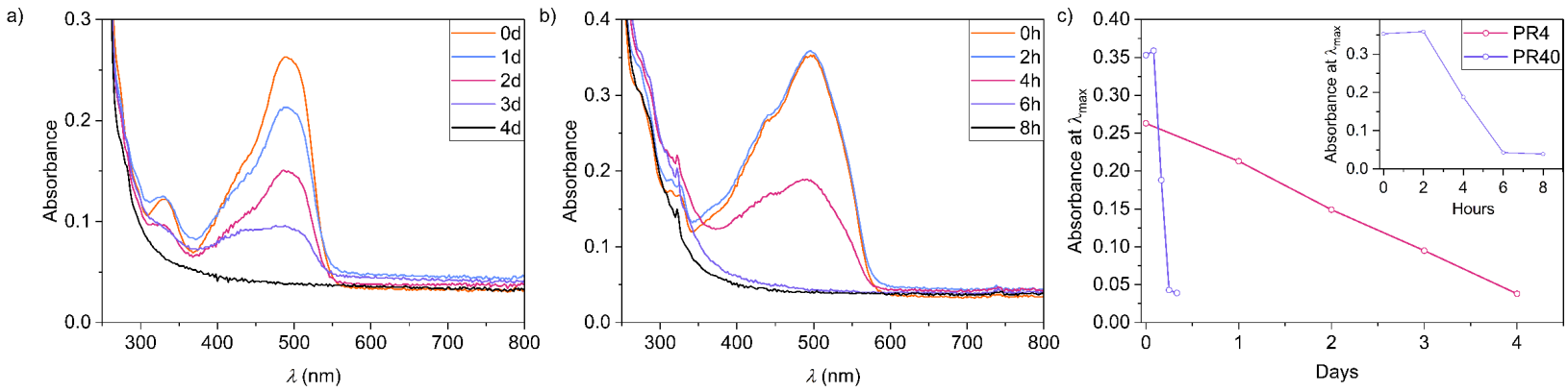

Figure 6. a) UV-vis spectra of PR4 dissolved in $\mathrm{CHCl}_{3}$ and irradiated at set time intervals b) UV-vis spectra of PR40 dissolved in Et2O and irradiated at set time intervals (c) plot of the change in absorbance at $\lambda_{\max }$ as a function of time.

Lightfastness. Lightfastness represents the degree and duration to which pigments and dyes resist fading due to constant light exposure. To study the long-term effects of UV-light on the pigments, we performed "accelerated light-aging" and photodegradation with strong UV irradiation. For this purpose, we used wavelengths above $\sim 295 \mathrm{~nm}$ as a simulation of sunlight, with a constant intensity of $900 \mathrm{~W} / \mathrm{m}^{2}$. Intense UV radiation of the pigments for $30 \mathrm{~h}$ in the solid-state did not result in degradation, as evidenced by a visual observation of color perseverance. To detect any possible degradation products, we collected micro-Raman spectra from the light-exposed surfaces of the samples. Figure 4 presents the Raman spectra before and after irradiation, without any visual changes in the scattering signature. To accelerate the photodegradation even further, we performed irradiation of dissolved pigments. Figure 6 presents the UV-vis spectra of solutions of PR4 and PR40 that were irradiated for various time intervals, showing gradual change of the absorbance at $\lambda_{\max }$ as a function of time. Over the course of the experiment, both pigments fully degraded, with a significant difference in the kinetics. Figure $5 \mathrm{c}$ presents the relative rate at which both pigments discolored. PR40 was shown to be relatively more prone to discoloration, as evidenced by complete degradation within $6 \mathrm{~h}$. Under identical condition, the degradation and discoloration of PR4 took four days. The likely reason for this difference is the presence of the para-positioned nitro group on the aryl ring in PR4. The nitro group, as a strong electronwithdrawing group, contributes to a less pronounced reactivity of the aryl ring, and the enol/keto bridge. ${ }^{28}$

Photodegradation Products. Identification and characterization of the photodegradation products is important for forensic studies of pigments, and for deriving conservation and preservation strategies. In an effort to identify some of the degradation products, we performed analysis of GC/MS data (Figures S3S6). Tables S2 and S3 lists several compounds for which GC/MS signatures match the observed peaks in our measurements. For example, 1-chloro-3-nitrobenzene and phthalamic acid were are proposed as degradation products of PR4, and naphthalene and 2-amino-1-acenaphthenone as degradation products of PR40. These compounds can be direct products of the photodegradation reactions of the starting pigments, or they can be produced by a multistep photodegradation cascade.

\section{CONCLUSIONS}

In summary, we present a comprehensive structural, spectroscopic, and thermal characterization of two prominent $\beta$-naphthol red pigments, PR4 and PR40. The SC-XRD analyses provided detailed descriptions of the solid-state, crystal structures. Both pigments crystallized in monoclinic space groups, $P 21 / c$ and $P 2_{1} / n$ for PR4 and PR40, respectively. After a careful inspection of the crystal structure, we conclude that, in the solid state, both pigments are comprised of the hydrazone isomer. Therefore, their description as "azo" pigments is erroneous and it should be avoided. PXRD studies confirmed that the bulk of the sample is composed of a single polymorph. IR and Raman spectroscopy corroborated the diffraction results. Furthermore, the presented spectral "fingerprint" region can serve for nondestructive identification and characterization. The thermal stability of both pigments was assessed with TGA and DSC measurements, showing stability up to $270{ }^{\circ} \mathrm{C}$ and $250{ }^{\circ} \mathrm{C}$ for PR4 and PR40, respectively, with melting of PR4 detected at $210^{\circ} \mathrm{C}$. The lightfastness of both pigments was studied under "accelerated light-aging" condition, mimicking strong sunlight. We conclude that PR40 discolors and decomposes at much higher rate, as compared to PR4. The para-positioned nitro group on the aryl ring in PR4 was identified as most likely reason for stabilization of the pigment. Some of the decomposition products where tentatively identified based on GC/MS analyses. In the solid-state, both pigments showed excellent lightfastness, as evidenced by micro-Raman spectroscopy. Overall, this study emphasizes the importance of crystallographic analyses for detailed characterization of pigments, and organic molecules in general. The presented results support proper chemical description and nomenclature of the pigments, assess their stability and help with the identification and characterization of degradation products. As such, they contribute to on-going pigments conservation research, and motivate further involvement of crystallography in art and heritage science.

\section{ASSOCIATED CONTENT}

\section{Supporting Information}

Photographs of single crystals of PR4 and PR40, crystallographic and Rietveld refinement data, GC chromatograms and mass spectra of irradiated pigments, and proposed degradation products. 


\section{Accession Codes}

CCDC Deposition Numbers 2142989 and 2142990 contain the supplementary crystallographic data for this paper. This data can be obtained free of charge by emailing data request@ (ccdc.cam.ac.uk, or by contacting The Cambridge Crystallographic Data Centre, 12 Union Road, Cambridge CB2 1EZ, UK; fax: +44 1223336033.

\section{AUTHOR INFORMATION}

\section{Corresponding Author}

truncevski@smu.edu

orcid.org/0000-0003-0886-8464

\section{ACKNOWLEDGMENT}

T.R. acknowledges the support by the Welch Foundation (Grant No.: N-2012-20190330) and the Sam Taylor Fellowship. M.P.H acknowledges the Hamilton Fellowship.

\section{REFERENCES}

(1) S., H. C.; Francesco, D.; L., van N. K.; Yvan, C.; Zenobia, J.; Stein-Erik, L.; Michel, M.; Renata, G.-M. A 100,000-Year-Old Ochre-Processing Workshop at Blombos Cave, South Africa. Science. 2011, 334 (6053), 219-222. https://doi.org/10.1126/science.1211535.

(2) Faulkner, E. B.; Schwartz, R. J. High Performance Pigments; Wiley, 2009.

(3) Delamare, F.; Delamare, G.; Guineau, B.; Francois, B Discoveries: Colors: The Story of Dyes and Pigments; DISCOVERIES (ABRAMS); Harry N. Abrams, 2000.

(4) Vetter, W.; Schreiner, M. Characterization of Pigment-Binding Media Systemscomparison of Non-Invasive in-Situ Reflection FTIR with Transmission FTIR Microscopy. e-Preservation Sci. 2011, 8, 10-22.

(5) Brunetti, B.; Miliani, C.; Rosi, F.; Doherty, B.; Monico, L.; Romani, A.; Sgamellotti, A. Non-Invasive Investigations of Paintings by Portable Instrumentation: The MOLAB Experience. Top. Curr. Chem. 2016, 374 (1), 1-35. https://doi.org/10.1007/s41061-015-0008-9.

Campos-Vallette, M. M.; Rodríguez, M. J.; Chapanoff, M. A.; Clavijo, E.; Gómez-Jeria, J. S.; Aliaga, A. E.; Jara, G. P.; Celis, F.; Paipa, C.; Leyton, P. SERS Spectrum of Red Dyes in the Mapuche Belts from the Beginning of the XXth Century. $J$. Raman Spectrosc. 2017, 48 (7), 958-965. https://doi.org/10.1002/jrs.5147.

(7) Standeven, H. A. L. The History and Manufacture of Lithol Red, a Pigment Used by Mark Rothko in His Seagram and Harvard Murals of the 1950s and 1960s. Tate Pap. 2008, 10, 1-8.

(8) Stenger, J.; Kwan, E. E.; Eremin, K.; Speakman, S.; Kirby, D.; Stewart, H.; Huang, S. G.; Kennedy, A. R.; Newman, R.; Khandekar, N. Lithol Red Salts: Characterization and Deterioration. e-PreservationScience 2010, 7, 147-157.

(9) Bekö, S. L.; Hammer, S. M.; Schmidt, M. U. Crystal Structures of the Hydration States of Pigment Red 57:1. Angew. Chemie Int. $\quad E d$. 2012, $51 \quad$ (19), 4735-4738. https://doi.org/10.1002/anie.201109082.

(10) de Groot, S.; van Keulen, H.; Megens, L.; van Oosten, T.; Wiersma, H. Discoloration of Plastics Objects: Investigation into Composition Using Various Analytical Techniques. In Future Talks 013-Lectures and workshops on Technology and Conservation of modern materials in design, 23/25 October 2013; Die Neue Sammlung-The Design Museum Munich, 2015; pp 19-26.

(11) Angelin, E. M.; França de Sá, S.; Picollo, M.; Nevin, A.; Callapez, M. E.; Melo, M. J. The Identification of Synthetic Organic Red Pigments in Historical Plastics: Developing an in
Situ Analytical Protocol Based on Raman Microscopy. J. Raman Spectrosc. 2021, 52 (1), 145-158.

Walsh, V.; Chaplin, T.; Siddall, R. Pigment Compendium: A Dictionary and Optical Microscopy of Historic Pigments; Taylor \& Francis, 2008.

Berrie, B. H.; Lomax, S. Q. Azo Pigments: Their History, Synthesis, Properties, and Use in Artists' Materials. Stud. Hist. Art 1997, 57, 8-33.

Angelin, E. M.; Oliveira, M. C.; Nevin, A.; Picollo, M.; Melo, M. J. To Be or Not to Be an Azo Pigment: Chemistry for the Preservation of Historical $\beta$-Naphthol Reds in Cultural Heritage. Dye. Pigment. 2021, $190 \quad$ (February). https://doi.org/10.1016/j.dyepig.2021.109244.

(15) Ball, P.; Nicholls, C. H. Azo-Hydrazone Tautomerism of Hydroxyazo Compounds—a Review. Dye. Pigment. 1982, 3, 526. https://doi.org/10.1016/0143-7208(82)80010-7.

(16) Harris, R. K.; Jonsen, P.; Packer, K. J.; Campbell, C. D. Carbon13 NMR of Solid Phenylazo-2-naphthols: Tautomerism and (13C, 14N) Residual Dipolar Coupling. Magn. Reson. Chem. 1986, 24 (11), 977-983.

Olivieri, A. C.; Wilson, R. B.; Paul, I. C.; Curtin, D. Y. Carbon13 NMR and $x$-Ray Structure Determination of 1-(Arylazo)-2Naphthols. Intramolecular Proton Transfer between Nitrogen and Oxygen Atoms in the Solid State. J. Am. Chem. Soc. 1989, 111 (15), 5525-5532.

(18) Luo, C.; Wang, H.; Dong, W.; Zhang, X. Theoretical Investigation on the Mechanism of the OH-Initiated Degradation Process of Reactive Red 2 Azo Dye $\dagger .2017$. https://doi.org/10.1039/c7ra05727j.

(19) Sema, A.; Aviyente, V.; Ince, H. Experimental and Modeling Approach to Decolorization of Azo Dyes by Ultrasound: Degradation of the Hydrazone Tautomer Go 1 kçe Tezcanli-Gu 1yer and Nilsun. 2005. https://doi.org/10.1021/jp046374m.

(20) CrysAlisPro. Oxford Diffraction Ltd. 2018.

(21) SCALE3 ABSPACK. Oxford Diffraction Ltd. 2005.

(22) Sheldrick, G. M. SHELXT - Integrated space-group and crystalstructure determination. Acta Crystallogr. Sect. A Struct. Chem. 2015, 71 (1), 3-8. https://doi.org/10.1107/S2053273314026370.

(23) Sheldrick, G. M. Crystal Structure Refinement with SHELXL. Acta Crystallogr. Sect. C Struct. Chem. 2015, 71 (1), 3-8. https://doi.org/10.1107/S2053229614024218.

(24) Dolomanov, O. V; Bourhis, L. J.; Gildea, R. J.; Howard, J. A. K.; Puschmann, H. OLEX2: A Complete Structure Solution, Refinement and Analysis Program. J. Appl. Crystallogr. 2009, 42 (2), 339-341. https://doi.org/10.1107/S0021889808042726.

(25) Rietveld, H. M. A Profile Refinement Method for Nuclear and Magnetic Structures. J. Appl. Crystallogr. 1969, 2 (2), 65-71. https://doi.org/10.1107/S0021889869006558.

(26) TOPAS-Academic-V6. Coelho Software: Brisbane 2018.

(27) Dent, G. Vibrational Spectroscopy of Colors, Dyes and Pigments Handbook of Vibrational Spectroscopy. December 20, 2001. https://doi.org/https://doi.org/10.1002/0470027320.s6905.

(28) Griffiths, J.; Hawkins, C. Oxidation by Singlet Oxygen of Arylazonaphthols Exhibiting Azo-Hydrazone Tautomerism. $J$. Chem. Soc. Perkin Trans. 2 1977, No. 6, 747-752. https://doi.org/10.1039/P29770000747. 